E-197 PULSERIDER FOR ANEURYSM RE-TREATMENT: COMBINED SUB-ANALYSIS OF THE ANSWER AND AWARD STUDIES

${ }^{1} \mathrm{~A}$ Spiotta*, ${ }^{2} \mathrm{D}$ Lopes, ${ }^{3} \mathrm{~J}$ Mocco, ${ }^{4} \mathrm{~A}$ Siddiqui, ${ }^{5} \mathrm{~S}$ Tateshima, ${ }^{6} \mathrm{H}$ Nahser. ${ }^{1}$ Department of Neurosurgery, University Hospital, Medical University of South Carolina, Charleston, SC; ${ }^{2}$ Brain and Spine Institute, Advocate Aurora Health, RUSH University, Park Ridge, IL; ${ }^{3}$ Department of Neurosurgery, Mount Sinai Hospital, New York, NY; ${ }^{4}$ Departments of Neurosurgery and Radiology, Jacobs School of Medicine and Biomedical Sciences, University at Buffalo, New York., Buffalo, NY; ${ }^{5}$ Department of Radiological Sciences, University of California, Los Angeles, Diagnostic and Interventional Radiology Diagnostic Radiology, Los Angeles, CA; ${ }^{6}$ The Walton Centre NHS Foundation Trust - Emeritus, Liverpool, UK

\subsection{6/neurintsurg-2020-SNIS.228}

Introduction PulseRider is a neck bridging device designed to aid in coiling of wide-neck intracranial aneurysms. When in place, it provides a 'floor' to the coil mass while allowing for easy access to the aneurysm sac, making it potentially suited for retreatment cases with limited working space.

Methods Procedural success and outcomes of retreatment cases included in the AWARD (Safety Study of the PulseRider in Patients Undergoing Treatment for Bifurcation Intracranial Aneurysms) and ANSWER (Adjunctive Neurovascular Support for Wide-neck aneurysm Embolization and Reconstruction) studies are presented.

Results Eleven PulseRider cases (10 female, mean age 50.9 years), 6 in AWARD and 5 in ANSWER, were retreatments of previously coiled aneurysms. Eight of the patients had 1 previous procedure, 2 had 2 previous treatments, and 1 had 3 , including a failed attempt at Y-stenting. Mean aneurysm neck size was $4.98 \mathrm{~mm}$ (range $3.0-11.6 \mathrm{~mm}$ ). Locations included basilar (7), carotid terminus (2) and MCA (2). PulseRider was successfully implanted with the ability to retain coils within the aneurysm in all cases. Immediately post-procedure, core lab adjudicated adequate occlusion rate was 91\% (4/11 [36\%] RR-I, 6/11 [55\%] RR-II and 1/11 [9\%] RR-III). At the one year follow up, the adjudicated rate of adequate aneurysm occlusion was $80 \%(6 / 10$ [60\%] RR-I, 2/10 [20\%] RR-II, and 2/10 [20\%] RR-III). There were no neurological deaths or major ipsilateral stroke (primary safety endpoint in the ANSWER study) and neurological decline was noted in one patient (the case of 3 previous treatments).

Conclusion Retreatment of previously coiled wide-neck aneurysms with the PulseRider device resulted in 100\% procedural success and $80 \%$ complete or near complete occlusion at 1 year with an acceptable safety profile.

Disclosures A. Spiotta: 1; C; Microvention. 2; C; Penumbra, Minnetronix, Cerenovus. 6; C; Cerenovus, Penumbra, Microvention. D. Lopes: None. J. Mocco: 2; C; Rebound Medical, LLC, Cerebrotech Medical Systems, Inc., Snchroyn, Inc., EndoStream Medical, Ltd.. 4; C; Apama Medical, Inc., NeuroTechnology Investors, LLC., NeurVana Medical, LLC, Cerebrotech Medical Systems, Inc., Synchron, Inc., EndoStream Medical, Ltd., Stroke Project, Inc. A. Siddiqui: 2; C; Amnis Therapeutics, Boston Scientific, Canon Medical Systems USA, Cerebrotech Medical Systems, Claret Medical, Corindus, Endostream Medical, Guidepoint Global Consulting, Imperative Care, Integra, Rapid Medical, Rebound Therapeutics Corp., Silk Road Medical, StimMed, Stryker, Three Rivers Medical, VasSol, W.L. Gore \& Associates, Cerenovus, Medtronic, MicroVention, Penumbra, Medical University of South Carolina, National PI/Steering Committee for POSITIVE Trial, Northwest University, DSMB Chair for HEAT Trial. 4; C;
Amnis Therapeutics, Apama Medical, BlinkTBI, Buffalo Technology Partners, Cardinal Health, Cerebrotech Medical Systems, Claret Medical, Cognition Medical, Endostream Medical, Ltd, Imperative Care, International Medical Distribution Partners, Rebound Therapeutics Corp, Silk Road Medical, StimMed, Synchron, Three Rivers Medical, Viseon. S. Tateshima: 2; C; Cerenovus, Medtronic, Neurovasc, Stryker. 4; C; Neurovasc. H. Nahser: None.

\section{E-198 FACIAL PAIN CAUSED BY A CAVERNOUS SINUS ANEURYSM TREATED WITH ENDOVASCULAR FLOW DIVERSION: CASE REPORT AND REVIEW OF THE LITERATURE}

A Larson*, T Mehta, A Grande. Neurosurgery, University of Minnesota, Minneapolis, MN

10.1136/neurintsurg-2020-SNIS.229

Flow diversion is a commonly-used endovascular modality to treat intracavernous aneurysms. Cases of intracavernous aneurysms causing facial pain are rare, and flow diversion may represent a viable treatment option in order to alleviate pain caused by these aneurysms. We present the case of a 53-yearold woman who presented with a two-year history of persistent, left-sided and facial pain and numbness located in the left V1-V2 distribution of the Trigeminal nerve. A brain MRI was obtained which showed a left internal carotid artery aneurysm projecting infero-laterally within the cavernous sinus and possibly compressing left V1 and V2 roots of the Trigeminal nerve. This was further investigated and confirmed with digital subtraction angiography. To reduce mass effect, the aneurysm was treated with flow-diversion rather than coilembolization. Her pain and numbness gradually improved with near-complete resolution at 6 months post-treatment. 6month follow-up angiography demonstrated minimal residual filling of the aneurysm suggesting a reduction in size of the aneurysm sac. This case, in addition to prior reports which we review here, demonstrate the ability of flow diversion to treat facial pain secondary to intracavernous aneurysms.

Disclosures A. Larson: None. T. Mehta: None. A. Grande: None.

\section{E-199 PRELIMINARY EXPERIENCE WITH SURPASS EVOLVE FLOWDIVERTER DEVICE: CLINICAL AND TECHNICAL NOTE}

${ }^{1} \mathrm{~K}$ Alpay*, ${ }^{1} \mathrm{R}$ Rautio, ${ }^{2} \mathrm{~J}$ Numminen, ${ }^{1} \mathrm{M}$ Sinisalo. ${ }^{1}$ Department of Radiology, Turku University Hospital, Turku, Finland; ' ${ }^{2}$ Department of Radiology, Helsinki University Hospital, Helsinki, Finland

\subsection{6/neurintsurg-2020-SNIS.230}

Objective The aim of the study to was to evaluate safety and efficacy of the new generation flow diverter device, Surpass Evolve (SE).

Methods In two Finnish early-user centers, twenty-seven patients with ruptured or unruptured intracranial aneurysms were treated with SEs. All procedure-related events were recorded into the local database for further analysis. We report here our results concerning the clinical and radiological 